\title{
КАНОНИЗАЦИЯ ИЛЬИ ЧАВЧАВДЗЕ И ЕЕ РОЛЬ В СОВРЕМЕННОЙ ГРУЗИНСКОЙ КУЛЬТУРЕ
}

\section{CANONIZATION OF ILYA CHAVCHAVDZE AND IT'S ROLE IN MODERN GEORGIAN CULTURE}

\section{P. Lebedeva}

Summary: The article analyzes the process of canonization and further veneration of the writer and prominent public figure llya Chavchavadze. The figure of Chavchavadze stands at the origins of the modern Georgian national identity. His understanding of the Georgian nation is still considered classic for the Georgian national idea. On the basis of the material presented, a conclusion is drawn about the root causes of this canonization.

Keywords: national culture, religion, modern Orthodoxy, modern religious cults, Georgia, Georgian culture, llya Chavchavadze.

\author{
Лебедева Параскева Викторовна \\ Аспирант, Санкт-Петербургский \\ Государственный Университет \\ paraskevalebedeva@mail.ru
}

Аннотация: В статье анализируется процесс канонизации и дальнейшего почитания писателя и видного общественного деятеля Ильи Чавчавадзе. Фигура Чавчавадзе стоит у истоков современного грузинского национального самосознания. Его понимании грузинской нации по сей день считается классическим для грузинской национальной идеи. На основе приведенного материала делается вывод о первопричинах этой канонизации.

Ключевые слова: национальная культура, религия, современное православие, современные религиозные культы, Грузия, грузинская культура, Илья Чавчавадзе.
$\mathrm{O}$ бщеизвестно, что центр православия на Кавказе находится в Грузии. Христианство неизменно являлось основополагающим элементом традиционной грузинской культуры с момента принятия христианства в начале IV веке н. э. После распада СССР, при строительстве нового независимого государства, Грузинская Православная Церковь (далее ГПЦ) стала принимать активное участие в общественно-политических и культурных процессах.

Из-за большого количества социальных проблем, образовавшихся в грузинском обществе после распада СССР, гражданское общество являло собой институт, не вызывающий доверия, в то время как церковь стала оплотом стабильности и традиционных воззрений. Всё чаще в обществе стал возникать вопрос, как понимать национальную идентичность, и насколько она связана с православием. Все эти процессы способствовали все большему вовлечению церкви во внутреннюю жизнь страны и активным попыткам создать идеологическое поле, которое смогло бы объединить нацию [4].

Характерный пример присваивания ГПЦ культурного наследия Грузии - это канонизация грузинского писателя, публициста и общественного деятеля Ильи Чавчавадзе.

Илья Чавчавадзе родился 8 ноября 1837 г. в кахетинском селе Кварели, его семья принадлежала к древнему княжескому роду. В 1857 г. он был зачислен на Юридический факультет Императорского университета в Санкт-
Петербурге, но не смог его закончить, т.к. был исключен в 1861 г. по причине участия в студенческих антиправительственных забастовках. По возвращению на родину он начал службу в государственных учреждениях, успешно совмещая её с литературной и переводческой деятельностью (переводил, в том числе на грузинский язык, и произведения русской классики). Активно выступал за освобождение крестьян, развитие сельского хозяйства, демократизацию общества. В 1879-1885 гг. он был заместителем председателя, а затем вплоть до своей кончины - председателем Общества распространения грамотности среди грузинского населения. Общество занималось организацией народных школ, издательством учебников, проведением различных научно-просветительских лекций и т.п. Чавчавадзе внес важный вклад в формирование современного грузинского языка. Он выступал против громоздкого, архаичного грузинского языка, активно вводил в употребление неологизмы, отстаивал необходимость преподавания грузинского языка в школах, издавал литературный журнал «Иверия», где публиковал произведения многих начинающих писателей и поэтов.

В 1906 г. он был избран членом Государственного Совета от дворянских обществ. Призывы Ильи Чавчавадзе к национально-демократической борьбе пользовались большой популярностью у народа, что, в свою очередь, привело к борьбе за идейное влияние с марксистами. В августе 1907 г. Чавчавадзе был застрелен в собственной коляске рядом с селом Цицамури. Обстоятельства его смерти до сих пор неясны. 
Чавчавадзе был сторонником либерально-националистического развития Грузии, из-за огромного влияния его именовали «некоронованным королем Грузии». Сегодня писателя называют «отцом отечества», а его имя часто фигурирует в текстах даже без фамилии или с эпитетом «великий».

Многие цитаты Чавчавадзе невероятно популярны сегодня в Грузии. Одна из самых цитируемых, используемая в качестве неформального девиза: «Три божественных сокровища осталось у нас от отцов и дедов: Родина, Язык, Религия. Если всем этим не овладеем, какой ответ отдадим потомкам» [1, с.24]. Суть государственной идеи, по Чавчавадзе, заключается в сохранении фундаментальных религиозных, культурных и национальных ценностей, он считает, что «защита этих ценностей - это вечная обязанность грузинского народа» [1, с. 25].

Возникновение современного грузинского национального самосознания неразрывно связано с идеями Чавчавадзе. Как отмечает Зеданиа Г., первым манифестом современного грузинского национализма можно считать его произведение 1861 г. «Записки проезжего. От Владикавказа до Тифлиса», где проявляются все «характерные аспекты, которые были на духу в течение последних 130-ти лет у грузинского национального движения» [5, с. 17]. Среди них - желание обрести независимость и избавиться от чужой власти, конфликт между традицией и современностью, убежденность в необходимости модернизации и пр. Автор статьи особо отмечает, что мы не видим в этом списке религиозной проблематики. Чавчавадзе призывает именно к секулярному национализму. Он считал, как пишет Зеданиа, что позиция православия незначительна для установления идентичности грузин, а главная роль в этом процессе принадлежит истории: «По нашему мнению, ни единство языка, ни единство религии и даже ни родство людей друг с другом не могут объединить так, как объединяет единство истории» [5, с. 17]. Именно идеи секулярного национализма Чавчавадзе разделяло грузинское общество вплоть до конца 80-х годов XX-го века, когда в 1987 г. (еще во времена существования (ССР) ГПЦ канонизировала Чавчавадзе в лике праведных.

Противники канонизации приводят некоторые факты, которые с их точки зрения не совместимы с канонизацией, как то: убийство известного писателя было не за Христа (что не позволяет считать его христианским мучеником), а за родину, признание святого не было всенародным явлением, а главное, канонизация была совершена «в угоду националистическим настроениям в обществе».

Официальные представители ГПЦ отрицают все предъявляемые обвинения и в ответ приводят доводы о благочестивой жизни Чавчавадзе и его преданной любви к родине. Канонизировав самого популярного грузинского общественного деятеля, церковь обозначила свои права на эту фигуру. Теперь в общественном пространстве обсуждение роли Чавчавадзе желательно только в дискурсе «Илья Праведный». Характерный пример - проведение научных конференций, посвященных Чавчавадзе, всегда знаменуется присутствием представителей ГПЦ.

Для примера рассмотрим конференцию, состоявшуюся в ноябре 2017 г. в Тбилиси. Научная конференция, посвященная «180-летию со дня рождения и 110-летию со дня смерти святого Ильи Праведного» [3] была проведена в патриаршей резиденции в присутствии самого католикоса и многочисленного сонма духовенства. После некоторого количества прочитанных докладов основатель благотворительного фонда имени св. Ильи Праведного, режиссёр Георгий Саванели, объявил об учреждении специальной премии в юбилейный год писателя. По единодушному решению членов фонда первым номинантом этой премии (им. Ильи Чавчавадзе) с формулировкой за «выдающийся вклад в развитие общества и объединение нации» стал католикос-патриарх Илья II [2]. С заключительной речью выступил сам католикоспатриарх, подчеркнув искупительную роль смерти писателя: «Илья Чавчавадзе был рождён агнцем. Он агнец Божий, взявший на себя грехи своего народа» [2].

Традиционно широко отмечаются всевозможные годовщины, связанные с писателем. Кроме огромного количества светских мероприятий (конференций, выставок, спектаклей, приуроченных передач и пр.) в программе торжеств всегда присутствует молебен св. Илье Праведному, который обычно открывает праздничные мероприятия.

В современной грузинской повседневной культуре И. Чавчавадзе также уделена значительная роль. Улицы, названные в честь «отца отечества», многочисленные памятники, музеи, его профиль на денежной купюре в двадцать лари, иконы с его изображением, которые обязательно присутствуют в каждом грузинском храме и пр.

\section{Выво $\Delta ы$}

Опираясь на свое возросшее положение, грузинская церковь смещает акценты и во внутрикультурном поле. Ярчайшим примером служит канонизация князя Ильи Чавчавадзе, которая произошла за несколько лет до распада СССР. Чавчавадзе в своих произведениях осмыслял единство грузинской нации, которое он предлагал созидать вокруг религиозных, культурных и национальных ценностей. Канонизировав этого общественного деятеля, грузинская церковь присвоила себе и его идеи, сменив секулярный дискурс на религиозный. 
В современном грузинском государстве церковь играет важную роль. Соединив национальные настроения с возрастающим интересом к традиционной религии, она смогла усилить свое влияние в обществе, что, в конечном итоге, сделало самым популярным гражданским институтом в стране.
Вот уже почти 40 лет, как церковь также заявила свои права на видного грузинского общественного деятеля, Илью Чавччавадзе. Его светские идеи трактуются теперь в рамках религиозного дискурса, а существующий светский культ постепенно обрастает деталями, свойственными культу традиционных православных святых.

\section{ЛИТЕРАТУРА}

1. Буадзе Т., Христианские ценности и общественно-политическое устройство // Гули гониери. 2017. № 18. с. $24-42$.

2. В патриархии прошла научная конференция, посвященная юбилею св. Ильи Праведного // официальный сайт ГПц. 13.11.2017. URL: http://patriarchate. ge/geo/wminda-ilia-martlis-iubilesadmi-midzghvnili/, (Дата обращения: 04.11.2020).

3. Конференция, посвященная 180-летию со дня рождения святого Ильи Праведного// Официальный сайт Тбилисской духовной академии и семинарии. 15.11.2017. URL: http://tsas.ge/ge/?p=2511 (Дата обращения: 04.11.2020).

4. Рцхиладзе Г. Религиозный фактор и конфликтный потенциал в Грузии // Центральная Азия и Кавказ. 2005.№ 3. С. 65-67.

5. Zedania G. Nationalizmus und Reigion in Georgia // G2W. 2011. № 6. S. 1-19.

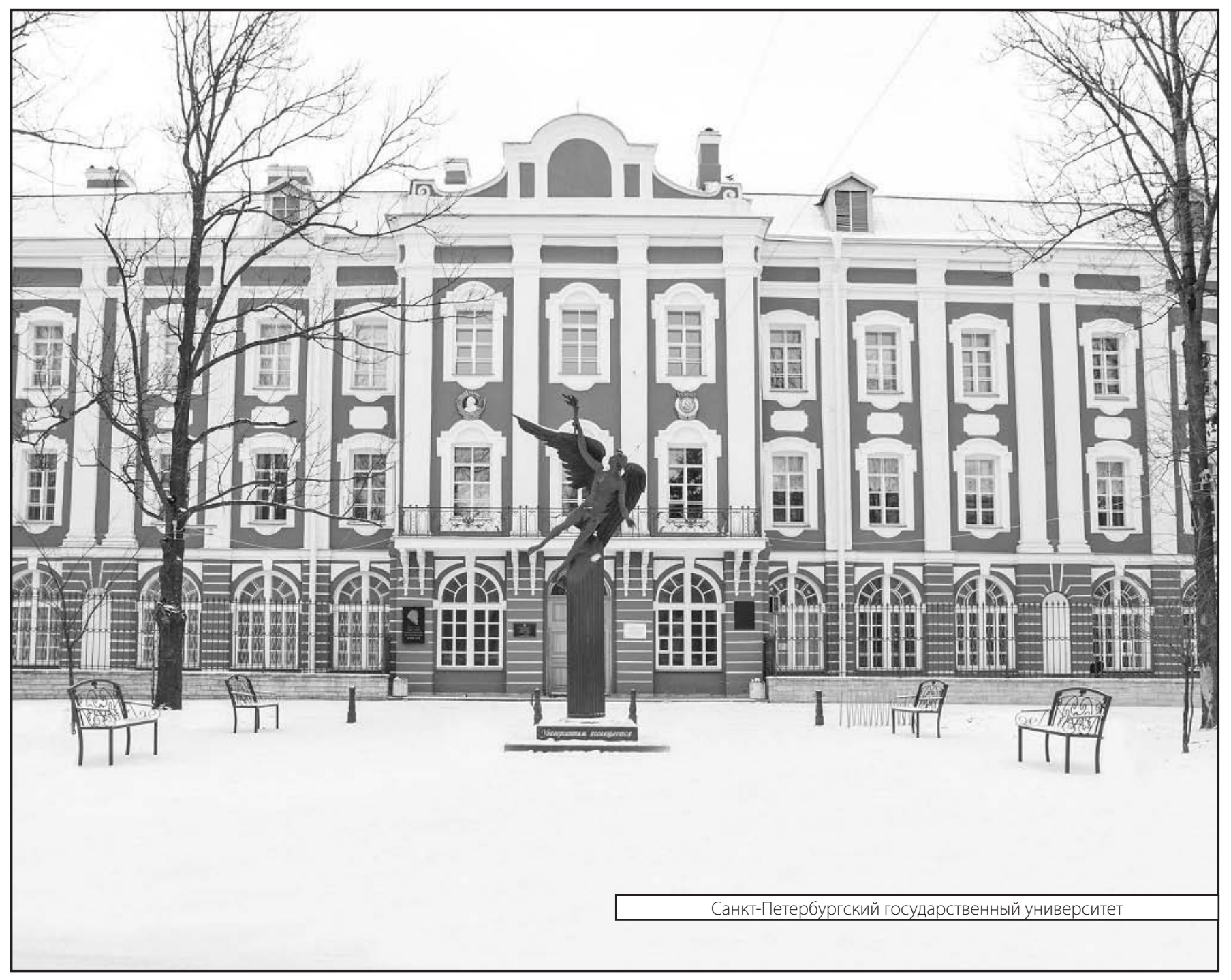

